evidence of the folly of the new vogue in universes. Here the appeal is certainly not to any criterion directly or indirectly implied in his definition of science, but to a social judgment. He points the finger at something which he conceives, rightly or wrongly, to be anti-social, because it involves wastage on studies not directly scientific. This is a very significant matter. It is importing a consideration that has become more and more prominent in the columns of scientific journals during the past few years. It asserts that the justification for a scientific inquiry is not entirely a narrow scientific one but rests also on its social value. It is an admission of the interconnexion of science with society, that the direction of scientific development, and therefore that the body of theory and practice embraced within science at any given time, is dependent on fundamental social, besides scientific, considerations. That he makes this judgment is itself a fact : hence on his own definition of science he must find a rational place for it within that definition. As it stands there is none. If he objects to the work of the mathematical speculators, he can do so at present only with respect to these phrases that purport to deny the necessity for observation. He cannot object to the expenditure of funds on such investigations, or to publications that are simply mathematical exercises in fictitious model universes.

Just as soon as we face up to this, these various problems begin to fall into a more integrated scheme. We state the position thus:

(1) Science is a social effort to understand, control and fashion Nature in accordance with developing human needs and desires.

(2) The method of science is an ever-growing and ever-deepening integration between experiment and inference, emerging in successive generalizations and successive applications to practice.
(3) Mathematics is an instrument designed to assist in the drawing of inferences from sets of data or of ideas, or what amounts to the same thing, to test such sets for their logical consistencies and inconsistencies. It is in the exposure of the latter that the deficiencies in the original data are made plain. Out of these deficiencies emerges a drive towards further experimentation.

Now when the mathematics under (3) can be regarded as accessory to the inferential processes of (2), and so can be integrated with experimental development, it can be said to have a place in science. This would include that part of pure mathematics that in the widest possible sense can be looked upon directly or indirectly as 'instrument-making'. In no circumstances can (3) ever replace (2).

To decide that a particular series of investigations ought to be encouraged, and, in particular, that it ought to receive the blessing of dominant scientific groups-and this is ultimately the question raised by Dr. Dingle-equally implies deciding to discourage other investigations, since the income to science is limited. Such a decision can emerge only from a thoroughly clear conception of what is implied in (1). It involves planning science pure and applied in its social context, and not following it indiscriminately for intellectual, financial or æsthetic interest; we are very far from that at the present moment, as the leader columns of NaTURE amply testify. Dr. Dingle is therefore tilting at one of the irrational features of social and scientific life. The fact that such irrationalism manifests itself in bold assertions of the type Dr. Dingle rightly deplores, that (3) can replace (2), is in such circumstances a natural consequence of the persistent refusal of scientific men to devote as much careful thought to science as a movement as they are prepared to give to their specialized fields.

\title{
Royal Observatory, Greenwich Annual Visitation
}

$\mathrm{T}$ HE annual visitation of the Royal Observatory, Greenwich, by the Board of Visitors took place on June 5.

The report of the Astronomer Roval includes for the first time an account of the work of the Nautical Almanac Office, which has been made a branch of the Observatory, with Mr. D. H. Sadler as a chief assistant and superintendent of the Office. It is of interest to recall that the Nautical Almanac originated with Maskelyne, the first volume appearing in 1765 , the year following his appointment as Astronomer Royal, and that the almanacs for fifty years were produced under his direction.

The Nautical Almanac Office has recently undertaken the compilation of an Air Almanac, specially adapted to the requirements of aerial navigation. The first issue will cover the last three months of the present year. The Air Almanac will give the air navigator the astronomical data in a convenient form; but the present methods for the subsequent computation are not suitable for conditions in the air. Extensive altitude and azimuth tables will be computed in the Office, which will give the solution of the spherical triangle directly.
The astronomical observations at Greenwich during the past year suffered inevitably from the poor observing conditions, the year having been one of the most cloudy on record. 6,573 transit observations were obtained, including 107 observations of the sun and 86 observations of the moon. The observations of the moon continue to show a decrease in the correction required by the longitude according to Brown's tables. These tables, however, include Newcomb's great empirical term and, when comparison is made with pure gravitational theory, the moon shows an increasing departure from its computed place. This departure is produced by variations in the rate of rotation of the earth. The accumulated effect of such variations in a year may at times amount to one second. The best astronomical clocks are scarcely sufficiently uniform in rate to detect such an error. It is possible that a clock of the vibrating quartz crystal type would have the desired accuracy. Such a clock is under construction for the Observatory at the National Physical Laboratory and should be of material help in improving still further the accuracy of the time signals sent out from the Observatory, which are necessarily based on predicted clock errors. 
The Observatory controls, by means of hourly signals, the Post Office Talking Clock, a service that was inaugurated by the Astronomer Royal on July 24. The calls on this clock are at the rate of ten million a year. It is intended to install similar clocks in other large centres.

The observations made with the Cookson floating telescope on a uniform programme for the past twenty-five years are under discussion. These observations have shown that the mean position of the Pole has not varied, during this period, by more than two or three feet.

The 28-inch refractor is being used for the general re-measurement of all double stars in the northern hemisphere, within the range of the telescope, that show appreciable motion in a decade. 692 observations on 238 double stars were secured. A comparison image micrometer has been constructed to facilitate and improve the accuracy of the measurement of close pairs. The filar micrometer will continue to be used for the wider pairs.

The projection method of measuring photographs has been applied to the micrometer used for the measurement of the stellar parallax plates. The star image and the micrometer wire system are projected on a screen, which is adjusted to the measurer's most comfortable reading distance, and both eyes are used, so avoiding eye fatigue.

Sunspot activity has increased greatly during the year. There were about twenty-five groups the maximum area of which exceeded 500 millionths of the sun's hemisphere. An intense magnetic disturbance, the largest for ten years, was associated with a large spot, the meridian passage of which occurred on April 24. The study of bright eruptions on the sun has been continued. These are becoming much more frequent with increasing solar activity; 72 were observed during the year. A close relationship between these eruptions and sudden fadings of short-wave radio transmissions has been established. The spectrohelioscope is being used also for measures of radial velocities, mostly in connexion with dark markings associated with sunspots, and of the maximum intensities of prominences and of bright and dark flocculi.
Magnetic observations were made at Abinger throughout the year. The mean values of the magnetic elements for the year 1936 were as follows :

$$
\begin{aligned}
& \text { Declination . . . W. } 11^{\circ} 20 \cdot 0^{\prime} \\
& \text { Inclination . } \quad . \quad \text {. } \quad 66^{\circ} 41 \cdot 8^{\prime} \\
& \text { Horizontal intensity . } \quad 0.18524 \text { gauss } \\
& \text { Vertical , . . } 0.43007 \text {, }
\end{aligned}
$$

Preliminary investigations in connexion with the new reversible transit circle have occupied much time. The figuring of the pivots was completed, the maximum departure of each pivot from the circular form being about one-twelfth of a micron. The errors of the one-degree divisions on the 24-inch fixed glass circle have been determined; these show a range of only $0 \cdot \mathbf{4}^{\prime \prime}$. Observations with the transit micrometer revealed some anomalies that required extensive investigation, and that necessitated the return of the micrometer to the makers for correction.

The slit spectrograph for use with the 36 -inch reflector has been completed. It has optical parts made of ultra-violet crown and flint glass, combined with quartz, being intended specially for work in the ultra-violet region. It can be used with a dispersion of either one or three prisms.

During the year, Mr. W. Bowyer, who had been in charge of the Time Department, retired after forty. four years' service and Mr. D. J. R. Edney, secretary, retired after nearly forty-five years' service.

The Astronomer Royal concludes his report with a reference to the difficulties connected with the installation of mercury vapour discharge lamps for lighting certain streets in the vicinity of the Observatory. Representations have been made to the Greenwich and Lewisham Borough Councils of the probable effects of the extension of such lighting along the roads across Blackheath. The two Borough Councils have expressed their desire to avoid interference with the work of the Observatory, and extensions of this system of lighting have been held in abeyance, so that possible alternatives could be thoroughly investigated.

\section{Rothamsted and Agriculture}

\section{Annual Inspection of the Rothamsted Plots}

A

LARGE and representative gathering met at Rothamsted on June 4 for the annual inspec. tion of the field plots and the laboratories. The Right Hon. W. S. Morrison, Minister of Agriculture, was present. Prof. H. E. Armstrong, recently elected chairman of the Lawes Agricultural Trust Committee, was unfortunately unable to attend owing to illhealth, but sent the following message :

"My connexion with Rothamsted goes back to 1870, when I first learnt to know Sir John Lawes and Dr. Gilbert. I am the only member of the original Trust Committee, established in 1898. I claim to have been instrumental in bringing both Sir Daniel Hall and Sir John Russell away from
Wye here. I have therefore accepted the Chairmanship of the Trust Committee with singular satisfaction, though I know full well that it is now beyond me to exercise much constructive control.

"We are at the close of our first critical period. We have acquired the Trust and purchased our rolease from Sir John Lawes' conditions. We owe this advance to our present Director : he has carried out a task of greatest difficulty, with conspicuous success, for which I, as Chairman, would thank him on behalf of my colleagues and the friends of agriculture in general.

"At first the work of the Trust was confined to the experimental fields, laid down by Sir John Lawes and Dr. Gilbert-no funds were available for other 